\title{
Patella dislocations and patellofemoral instability: a current concepts review
}

\author{
Benjamin R Garrett, (D) Michael L Grundill* \\ Department of Orthopaedic Surgery, Livingstone Tertiary Hospital, Port Elizabeth, South Africa \\ *Corresponding author: mlgrundill@gmail.com
}

Citation: Garrett BR, Grundill ML. Patella dislocations and patellofemoral instability: a current concepts review. SA Orthop J 2021;20(3):167-177. http://dx.doi. org/10.17159/2309-8309/2021/ v20n3a6

Editor: Prof. Michael Held, University of Cape Town, Cape Town, South Africa

Received: December 2020

Accepted: April 2021

Published: August 2021

Copyright: @ 2021 Garrett $\mathrm{BR}$, Grundill ML. This is an open-access article distributed under the terms of the Creative Commons Attribution Licence, which permits unrestricted use, distribution and reproduction in any medium, provided the original author and source are credited.

Funding: No funding was received for this study.

Conflict of interest: The authors declare they have no conflicts of interest that are directly or indirectly related to the research.

\begin{abstract}
Lateral patellar dislocation affects young, active patients with an incidence rate of 5.8 per 100000 . The management of first episode dislocations is non-surgical in the majority of cases, unless associated pathology dictates surgical intervention. Approximately $40 \%$ of cases that are treated non-surgically will develop recurrent patellofemoral instability. Evidence supports surgical intervention in these cases; however, the best approach is debatable. Most research and consensus statements agree that medial patellofemoral ligament reconstruction (MPFLR) should be performed in most cases. Additional procedures can be used 'a la carte' according to certain conditions or pathology. A tibial tubercle osteotomy (TTO) is usually indicated in patients with maltracking and/or patella alta, but the direction and degree of correction must be carefully considered. Trochleoplasty is technically demanding and should be reserved for a select few patients with severe trochlear dysplasia. It should be performed by an experienced knee surgeon due to the high risk of inadvertent complications.
\end{abstract}

Level of evidence: Level 5

Keywords: patellofemoral instability, patellar dislocation

\section{Introduction}

Patellofemoral instability is defined as symptomatic deficiency of the soft tissue, muscular and bony constraints maintaining the patella within the trochlear groove, such that the patella may escape either partially or completely from its asymptomatic position as the knee flexes. ${ }^{1}$ Patellar dislocation is a relatively common problem, with an incidence of 5.8 per 100000 affecting young, active patients with an increased risk in adolescent females. ${ }^{2,3}$ It is best described by direction of instability with degree of flexion. As such, lateral instability in early flexion $<45^{\circ}$, lateral instability in late flexion $>45^{\circ}$, medial instability and multidirectional instability can be differentiated. This article will focus on lateral instability in early flexion. ${ }^{1}$ The aetiology of instability and dislocation can be attributed to an initial traumatic event or to underlying bone and soft tissue abnormalities ${ }^{4}$ (Table I).

The recurrence rate after nonoperative management may be higher than $40 \%,{ }^{2}$ and literature suggests that up to $55 \%$ of patients with first-time dislocations do not return to sport after an initial dislocation. ${ }^{5}$
Management is aimed at preventing recurrent dislocations. However, despite substantial evidence on the topic, the ideal strategy for first-time lateral patellar dislocation remains controversial. ${ }^{6}$ Following conservative treatment for a first-episode dislocation, one-third of patients have good outcomes, one-third will have recurrent instability and require surgical intervention, and onethird of patients will not have recurrence - but will have persistent symptoms of pain and instability. ${ }^{7}$ Since the landmark work in 1994 by Dejour et al., ${ }^{8}$ which identified four anatomical risk factors (trochlear dysplasia, patella alta [Caton-Deschamps index $\geq 1.2$ ], patellar tilt $\geq 20^{\circ}$ and tibial tuberosity-trochlear groove [TT-TG] distance $\geq 20 \mathrm{~mm}$ ), two schools of thought have emerged in the management of these patients. The first approach is to deal with each of the underlying anatomical abnormalities on an 'à la carte' basis, ${ }^{8}$ as compared to a standardised surgical approach, which involves performing an isolated MPFL reconstruction. ${ }^{9}$ Despite low-level evidence supporting either strategy, a combination approach has evolved, which involves performing an MPFL reconstruction along with correcting additional major risk factors. ${ }^{10,11}$ The difference between this method and the initial 'a 


\begin{tabular}{lll} 
Soft tissue & Bony & Malalignment \\
\hline - Medial laxity (e.g. incompetent medial patellofemoral ligament, & - Trochlea dysplasia & - Lateralised tibial tubercle \\
vastus medialis obliquus weakness) & - Patella alta & Increased Q-angle \\
- Lateral tightness (e.g. iliotibial band) & & Increased femoral anteversion \\
- Global laxity (e.g. Marfan syndrome, Ehlers-Danlos syndrome) & Increased tibial torsion \\
\hline
\end{tabular}

la carte' approach, is the addition of an MPFL reconstruction along with selective correction of major associated anatomical problems. An isolated MPFL reconstruction has been shown to be sufficient for low magnitude and low number of risk factors. However, the point at which this isolated procedure will fail and correction of additional factors is required is not fully understood..$^{12}$ In skeletally immature patients there are additional considerations due to open physes. Regardless of the treatment strategy, the initial assessment remains critically important and involves a thorough history, clinical examination as well as imaging to quantify the problem and guide decision-making.

\section{Pathoanatomy}

The biomechanics of the patellofemoral joint (PFJ) rely on the interplay between bony congruence and associated soft tissue static and dynamic constraints, to achieve joint stability throughout the range of motion. The mechanism of traumatic lateral patellar dislocation usually occurs with the knee in slight flexion with an associated valgus force, or by direct medial force to the patella. ${ }^{13}$ The PFJ is most unstable in full extension, and stability improves as the patellar engages the femoral trochlea during flexion under normal circumstances. During the first $30^{\circ}$ of flexion the MPFL has been shown to be important in preventing lateral translation. A recent anatomical study has shown the potential importance of associated medial structures, namely the medial patellotibial ligament (MPTL), and medial patellomeniscal ligament (MPML). The mean failure load for the MPFL, MPTL and MPML was $178 \mathrm{~N}$, $147 \mathrm{~N}$ and $105 \mathrm{~N}$, respectively. No significant difference was found between the MPFL and MPTL or between the MPTL and MPML. However, a significant difference was found between the MPFL and MPML. Interestingly the vast majority of failures occurred midsubstance. Both the semitendinosus and gracilis tendons would be appropriate graft options as their load failures exceed that which is described above $\left(1216 \mathrm{~N}\right.$ and $838 \mathrm{~N}$ respectively). ${ }^{14}$ The effects of the MPFL on PFJ stability has been widely investigated and is thought to be mostly isometric during the flexion arc of the knee joint. Work by Amis et al. showed that the MPFL is tightest when in full extension and early flexion. ${ }^{15}$ Its origin is on the medial femur, approximately $4 \mathrm{~mm}$ distal and $2 \mathrm{~mm}$ anterior to the adductor tubercle, and inserts onto the proximal half of medial patella. ${ }^{16,17}$ Lateral tightness can also contribute to instability and is usually as a result of a tight iliotibial band and/or capsule. Beyond $30^{\circ}$ of flexion, the congruence between the patella and trochlea becomes the primary restraint. For this reason, patella alta (high-riding patella) can lead to lateral instability by increasing the distance travelled before engaging the trochlea. ${ }^{4}$ Trochlear dysplasia and its variants may result in loss of the guiding effect on the patella beyond $30^{\circ}$ of flexion causing lateral instability. ${ }^{4}$ The aetiology of trochlear dysplasia is largely unknown; however, it is postulated to have both genetic and developmental origins. ${ }^{18,19}$ Dejour et al. found that $96 \%$ of patients with a history of a true patellar dislocation had evidence of trochlear dysplasia. ${ }^{8}$ The position of the tibial tubercle determines the force vector of the patellar tendon on the patella; therefore, a laterally based tubercle can cause lateral pull resulting in instability. The alignment and rotational profile of the lower limb may have a contributing effect on PFJ stability. External tibial torsion and/or internal femoral torsion will result in an increased lateral force vector, especially during terminal extension, which is accentuated by the screw-home mechanism of the knee. ${ }^{4}$ Valgus coronal plane deformity will also contribute to this effect. The vastus medialis oblique (VMO) is often the first quadriceps muscle to weaken during functional impairment and can result in muscular imbalance causing lateral instability. ${ }^{20}$

\section{Clinical evaluation}

A detailed history should include the age, sex, skeletal maturity, level of sport and expectation to return to competitive activity. The mechanism of injury and position of limb during dislocation should be noted as this may identify underlying pathology in subtle cases. Subsequent episodes need to be recorded and the presence of pain, deformity and disability needs to be identified. There is often an overlap of pain and instability symptoms which need to be evaluated independently.

A thorough gait and alignment examination may reveal valgus knees with potential thrusting. Rotational profile must be carefully checked to exclude femoral and/or tibial torsional problems. A particular combination of deformities was described by James et al. ${ }^{21}$ as the 'miserable malalignment syndrome'. These include valgus knees, increased femoral anteversion, pronation of the foot and external tibial torsion. The quadriceps should be evaluated for VMO wasting and the $Q$ angle determined by measuring the angle between the line connecting the anterior superior iliac spine and the patella with the line connecting the patella and tibial tuberosity in extension. ${ }^{22}$ Overall, the reliability of the Q-angle measurement has been questioned and evidence suggests that it should not be used. $23-26$

Examine the knee for possible haemarthrosis. Patellar dislocation is the most common cause of traumatic haemarthrosis in children, and the second most common in adolescents after anterior cruciate ligament injuries. ${ }^{27}$ Tenderness (Bassett sign) over the medial femoral condyle should be elicited. Anterior knee pain and/or positive patellofemoral grind (Clarke's test) may indicate underlying osteochondral damage. Patellar tracking should be noted along with a possible $\mathrm{J}$-sign (lateral subluxation of the patella when actively moving knee from flexion into extension). ${ }^{28}$ Lateral glide (Sage sign) of the patella should not exceed two quadrants (compare to contralateral side). ${ }^{29}$ The most sensitive $(100 \%)$ and specific test $(88.4 \%)$ for patellar instability is the moving patellar apprehension test as described by Ahmad et al. (a two-part test performed by taking the knee from full extension into flexion with a laterally directed force on the patella, resulting in apprehension and involuntary quadriceps activation to prevent further knee flexion. The second component again involves taking the knee from extension to flexion, this time with a medially directed force on the patella. A positive test shows no apprehension in this phase and the patient allows the knee to be fully flexed ${ }^{30}$ ). Features of connective tissue disorders such as Ehlers-Danlos and Marfan syndromes should be sought, along with a general ligamentous laxity Beighton score if indicated. ${ }^{31}$

\section{Radiographic evaluation}

Basic evaluation begins with four standard X-ray views, including an anteroposterior (AP), lateral, Rosenberg weight-bearing 

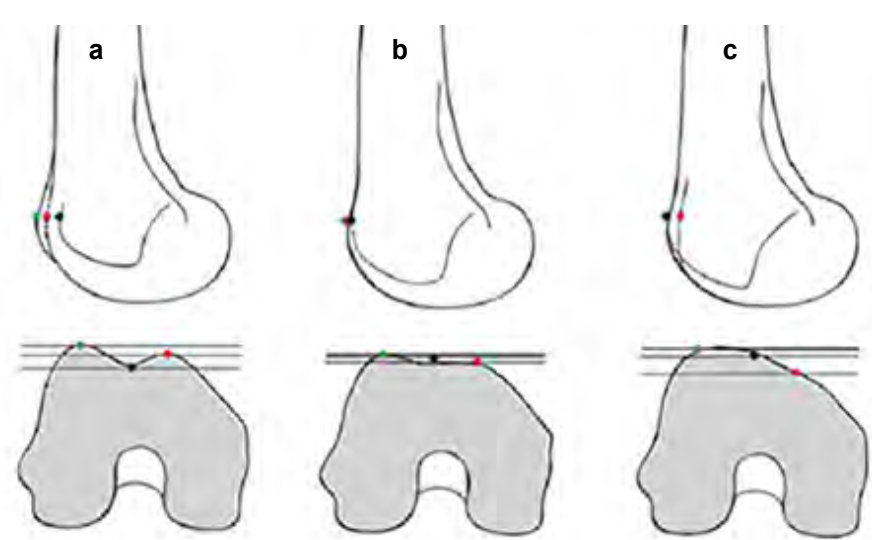

Figure 1. Radiographic features of patellofemoral dysplasia a) Normal; b) Crossing sign; c) Double contour sign

(Adapted from Zaffagnini et al. The patellofemoral joint: from dysplasia to dislocation. EFORT Open Rev. 2017;2(5):204-14. Use permitted under Creative Commons licence CC-BY-NC 4.0)

bent-knee posteroanterior (PA) and a sunrise (bent-knee axial) as per the seminal paper by Dejour et al. ${ }^{8}$ Should there be any concern about coronal alignment, long-leg standing views of the legs should be performed. A lateral view of the knee in $30^{\circ}$ flexion allows evaluation of the trochlea, as well as the patellar height. Three lines are evaluated on the lateral view, and include the two most anterior lines which represent the superimposed femoral condyles, followed by the third line which represents the trough of the trochlea groove. In a normal knee, the line representing the trochlea groove does not intersect the lines representing the femoral condyles. Evidence of trochlear dysplasia is thus demonstrated by the third line crossing the femoral condyles, the so-called crossing $\operatorname{sign}^{32}$ (Figure 1). Evidence of a trochlear bump/ spur is evaluated with a line drawn along the anterior cortex of the femur, where the trochlea groove may either be anterior, posterior or neutral to this line. A trochlear groove line $>3 \mathrm{~mm}$ anterior to this line represents a pathological spur/bump which may act like a ramp pushing the patella laterally ${ }^{33,34}$ (Figure 2). The double contour sign is represented by a line below the trochlear groove line on lateral view, representing a hypoplastic medial condyle. These findings form the basis of the Dejour classification of trochlear dysplasia, which is divided into four types (Figure 3). ${ }^{33,35}$ The Dejour classification system helps to guide management, and patients with types $B$ and $D$ may benefit from trochleoplasty. ${ }^{33,36}$ Recently a new MRI classification system, the OswestryBristol classification, has emerged and appears to have improved inter- and intra-observer reliability as compared to the Dejour classification. This classification grades trochlea dysplasia as normal, mild, moderate and severe, with severe cases requiring trochleoplasty according to the suggested algorithm ${ }^{37}$ (Figure 4).

Axial views of the knee are also very useful in identifying trochlear dysplasia, patellar tilt and subluxation. On the sunrise view, patellar tilt (Laurin's angle) and subluxation (Merchant's congruence angle) can be quantified. The Merchant congruence angle view requires knee flexion of $45^{\circ}$ with the X-ray beam angled at $30^{\circ}$ caudally, and is usually $6-11^{\circ}$ medial..$^{38}$ The sulcus angle can be calculated by measuring the angle between the intercondylar trough and the femoral condyles. An angle greater than $145^{\circ}$ is diagnostic of trochlear dysplasia. A patellar tilt

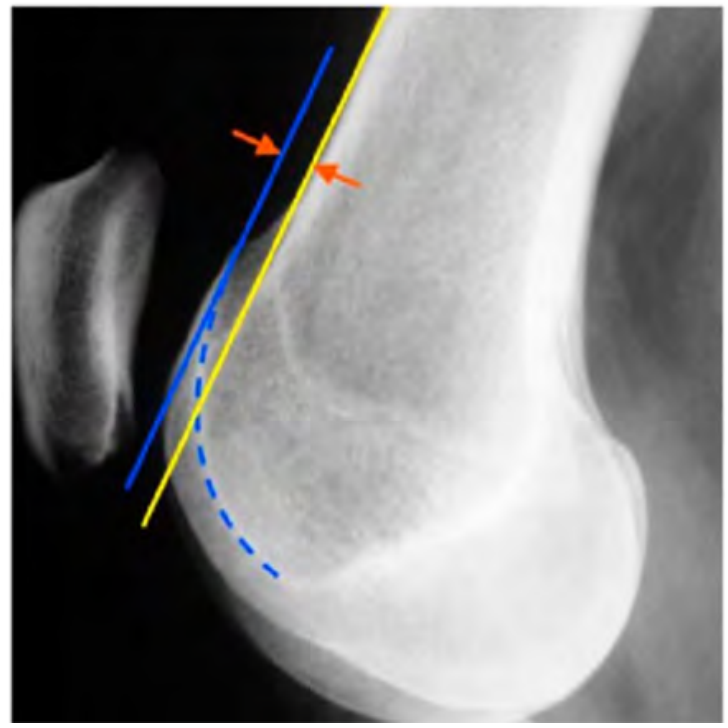

Figure 2. Trochlear bump: yellow line represents anterior femoral cortex; blue line represents the floor of the trochlea

(Adapted from Batailler C, Neyret P. Trochlea dysplasia: imaging and treatment options. EFORT Open Rev. 2018;3(5):240-47. Used with permission from corresponding author Philippe Neyret)

angle less than $5^{\circ}$ is normal. ${ }^{8}$ Patellar alta can be assessed on lateral radiographs using various ratios between the patella and the tibia/tibial tubercle. These include the Blackburne-Peel ratio, ${ }^{39}$ Insall-Salvati ratio, ${ }^{40}$ Koshino ratio ${ }^{41}$ and the Caton-Deschamps ratio $^{42,43}$ (Figure 5). Most surgeons prefer to use the CatonDeschamps ratio as it is less reliant on the flexion position of the knee and better reflects the articulating portion of the patellofemoral joint. ${ }^{44} \mathrm{~A}$ Caton-Deschamps ratio greater than 1.2 indicates patella alta. Advanced imaging in the form of computed tomography (CT) and/or magnetic resonance imaging (MRI) is recommended for assessment of the underlying pathology prior to any surgical intervention and to exclude associated injuries in acute patella dislocations. High-resolution, cross-sectional imaging using CT

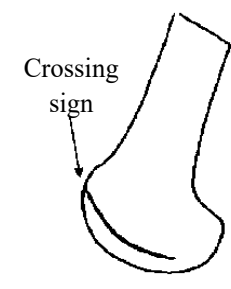

Shallow trochlea

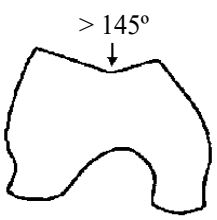

Dysplasia Type A

D. Dejour
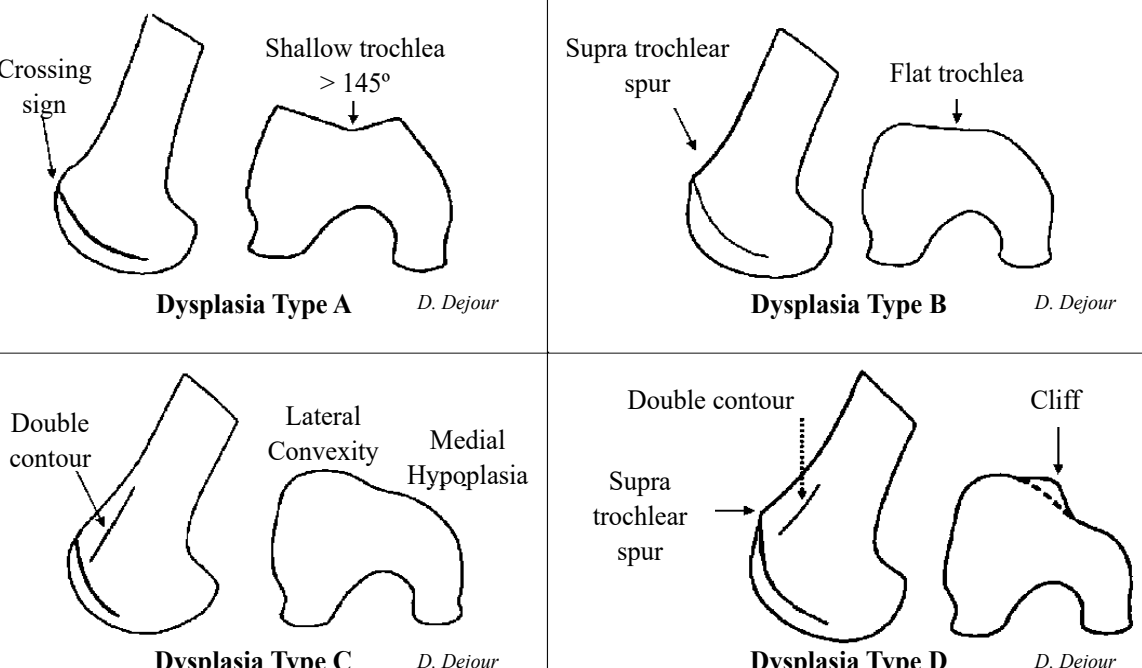

Figure 3. Dejour classification. Type A: Crossing sign on the lateral view, shallow trochlea, sulcus angle $>145^{\circ}$ on the axial view (shallow trochlea). Type B: Crossing sign, supratrochlear spur/bump on lateral radiographs (flat or convex trochlea). Type C: Crossing sign, double contour sign (asymmetry of trochlear facets with a hypoplastic medial condyle). Type D: Crossing sign, supratrochlear spur/bump, double contour sign (asymmetry of trochlear facets plus vertical join and cliff pattern)

(Reproduced with permission from David Dejour. Original article: Dejour D, Reynaud $\mathrm{P}$ Lecoultre B. Douleurs et Instabilite Rotulienne. Essai de classification. Med Hyg. 1998;56:1466-71) 


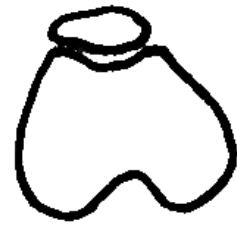

Normal

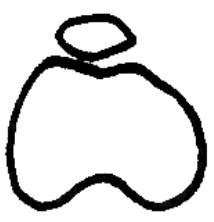

Mild trochlear dysplasia

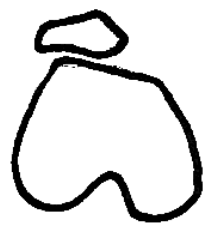

Moderate trochlear dysplasia

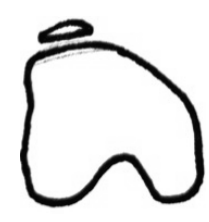

Severe trochlear dysplasia

Figure 4. Author's diagrammatic representation of the Oswestry-Bristol Classification

(Adapted from Sharma et al. The Oswestry-Bristol Classification: a new classification system for trochlear dysplasia. Bone Jt J. 2020;102(1):102-107)

accurately demonstrates trochlear dysplasia and rotational abnormalities of the tibia and femur. Furthermore CT imaging is used to calculate the tibial tubercle-trochlear groove (TT-TG) distance, and when more than $20 \mathrm{~mm}$ is associated with patellar instability 8.45 (Figure 6). It is important to note that knee flexion influences the measurement significantly, with the TT-TG distance shortening by $1 \mathrm{~mm}$ for every $5^{\circ}$ of flexion, as described by Tanaka et al. ${ }^{46}$ If there are any clinical suspicions of associated soft tissue and cartilage injuries, or concerns over radiation exposure, an MRI may be better indicated. MRI demonstrated $85 \%$ sensitivity and $70 \%$ specificity in identifying associated MPFL injuries ${ }^{47}$ Cartilage injuries can be expected in $70-90 \%$ of acute and recurrent dislocations. ${ }^{48-50}$ Patellar height can also be assessed using the MRI-derived patella-trochlear index which measures the ratio of trochlea cartilage to patellar cartilage on a mid-sagittal view with the knee in extension. A measurement of $12.5 \%$ indicates patella alta, whereas a measurement of $>50 \%$ indicates patella baja. ${ }^{24}$ The TT-TG distance can also be measured using MRI imaging; however, it has been shown to underestimate the distance by $3.8 \mathrm{~mm}$ when compared to $\mathrm{CT} .{ }^{51}$ Furthermore, some clinicians believe that the position of the tibial tubercle is affected by knee rotation and therefore a more accurate measurement should reference from tibial structures alone. Thus the tibial tubercleposterior cruciate ligament distance has been developed to assess lateralisation of the tibial tubercle which is independent of knee flexion. ${ }^{52,53}$ Other MRI-based measurements include the sagittal patellofemoral engagement index which acts as a supplementary assessment of patellar height, and the axial engagement index which indicates lateral patellar displacement. ${ }^{54,55} \mathrm{MRI}$ has also been used to accurately measure trochlea depth, sulcus angle and facet asymmetry. ${ }^{56} \mathrm{MRI}$ may be more accurate in grading trochlear dysplasia when compared to the X-ray-based Dejour classification. ${ }^{57}$

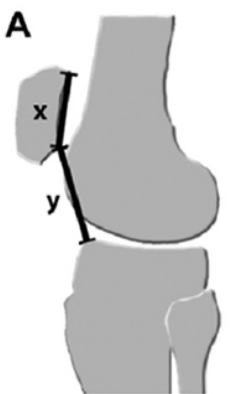

Caton-Deschamps

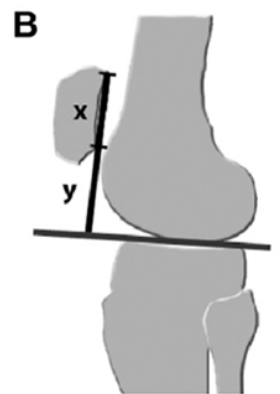

Blackburne-Peel

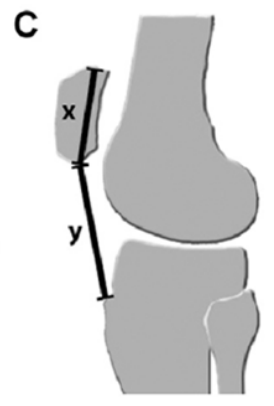

Insall-Salvati
Figure 5. Radiographic methods for evaluating patella alta on lateral X-ray of the knee

(Adapted from: Mayer $\mathrm{C}$ et al. Patellar tendon tenodesis in association with tibial tubercle distalization for the treatment of episodic patellar dislocation with patella alta. Am J Sports Med. 2012;40(2):346-51. Used with permission from the corresponding author, Robert Magnussen)

\section{Quantifying risk of dislocation}

In order to predict the risk of recurrence and guide management, attempts have been made to quantify the cumulative effect of risk factors. According to Lewallen et al., the risk of recurrence in young patients ( $<25$ years) is $27 \%$, whereas if the patient has trochlear dysplasia the risk is $23 \%$. On an individual basis, one might not consider surgery for either of the above situations after a primary dislocation; however, if these individual risk factors are combined, the exponential cumulative risk is $60 \%$ and the threshold for surgery is lower. ${ }^{58}$ Steensen et al. ${ }^{4}$ showed that $60 \%$ of recurrent dislocations had two or more associated risk factors and this was validated by a finite element model by Fitzpatrick et al. ${ }^{59}$ which used a prediction algorithm based on variable weighting of risk factors showing a $90 \%$ sensitivity and $87.5 \%$ specificity respectively. Hiemstra et al. grouped their patients into either WARPS (weak, atraumatic, risky anatomy, pain and subluxation) or STAID (strong, traumatic, anatomy normal, instability and dislocation) categories which allows a relatively simple approach to prognostication and management. ${ }^{60}$ Balcarek et al. introduced the patellar instability severity score (ISS), which identifies six risk factors: age ( $<16$ years), bilateral instability and four anatomic risk factors measured on MRI (trochlear dysplasia, patellar height, TT-TG distance and patellar tilt). An ISS of more than 4 has a five times higher odds ratio of recurrence. ${ }^{61}$ There is a good correlation between the WARPS/STAID system and the ISS. ${ }^{60}$

\section{Management guidelines}

The correct treatment of primary and recurrent lateral patellar dislocation may be a dilemma and should be determined on an individual basis. There are many potential surgical procedures, used in various combinations, which make direct comparisons in the literature difficult.

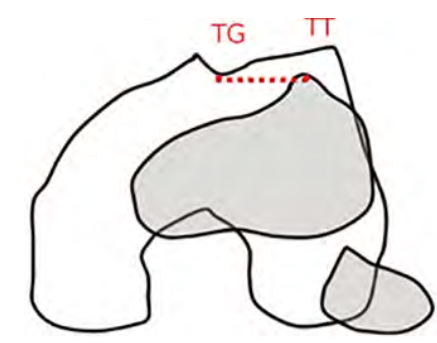

Figure 6. TT-TG distance measurement: Axial image of the deepest portion of the trochlear groove is marked and superimposed onto an axial image where the tibial tubercle can be marked. The distance between these two points is then measured.

(Adapted from Zaffagnini et al. The patellofemoral joint: from dysplasia to dislocation. EFORT Open Rev 2017;2(5):204-14. Use permitted under Creative Commons licence CC-BY-NC 4.0) 
The initial aim is to decrease swelling which can hinder quadriceps muscle activity. Adequate assessment is required to confirm that the correct diagnosis is made (not cruciate or collateral ligament or meniscus injury); to exclude associated injuries (osteochondral fracture of the lateral femoral condyle or patella) which may require MRI and early surgery; to assess risk factors for recurrence with appropriate imaging modalities (young age, sports-related injury, patella alta, skeletal immaturity and trochlear dysplasia) and to counsel appropriately.

\section{Nonoperative management}

Conservative treatment is supported in most cases of first-time acute lateral patellar dislocations without associated osteochondral fractures. Reported recurrence rates vary between $15 \%$ and $44 \%$, and $50-60 \%$ of patients report residual limitations to activity after conservative treatment. There is also growing evidence showing that the rate of re-dislocation is significantly lower following early operative reconstruction., 2,5,6,62-72 Indications for surgery after a first episode dislocation may be influenced by using predictive tools as described above. This may result in cases being treated operatively which otherwise may have been treated nonoperatively.

\section{Immobilisation and bracing}

Most commonly, a period of three to six weeks of immobilisation is followed by progressive increase in mobility over time. Longer periods of immobilisation in a cast or posterior splint can cause stiffness, weakness and loss of proprioception. ${ }^{73-78} \mathrm{~A}$ position of $20^{\circ}$ of knee flexion places the least amount of strain on the injured MPFL. ${ }^{15}$ Knee braces (hinged or lateral stabilisation) may decrease patients' subjective feeling of patellar instability and improve patella tracking while allowing earlier free range of motion. ${ }^{79-83}$

\section{Physical therapy}

Physiotherapy is recommended for regaining early range of motion, quadriceps/gluteal strengthening and vastus medialis oblique (VMO) conditioning, specifically following closed-chain exercises and core stability exercises. ${ }^{82}$ Gait re-education and landing technique in sports may be important. ${ }^{76,77,79,82}$ There is little difference between non-, partial and full weight-bearing status. McConnell taping may help to control excessive patella motion during therapy and increase quadriceps muscle torque and activate VMO earlier than vastus lateralis during stair ascent and descent. It allows earlier functional rehabilitation, is easy to apply and is cheap. ${ }^{78,84-86}$ Return-to-sports guidelines follow the same principles of recovery as most knee injuries and occur in a stepwise manner as described by Ménétrey et al. and Respizzi and Cavallin..$^{87,88}$
Table II: The principles of surgical intervention based on the pathoanatomy of PFJI

\begin{tabular}{ll}
\multicolumn{1}{c}{ Pathoanatomy } & \multicolumn{1}{c}{ Surgical options } \\
\hline Instability without malalignment & MPFL reconstruction \\
\hline Instability with malalignment & Tibial tuberosity medialisation + MPFLR \\
\hline Instability with patella alta & Tibial tuberosity distalisation + MPFLR \\
\hline Trochlear dysplasia & Trochleoplasty + MPFLR \\
\hline Rotational problems & Derotation osteotomy \\
\hline
\end{tabular}

\section{Surgical management}

Patella stabilisation is indicated for those with recurrent instability that are symptomatic with continued apprehension despite conservative treatment. ${ }^{2,89}$ Early stabilisation may also be considered for those with significant anatomic abnormalities. Many authors recommend that the correct procedure is performed in a specialised unit with a multidisciplinary team and governance systems in place to review practice. Lateral patellar instability in early flexion $\left(0-30^{\circ}\right)$ is the most common problem warranting early surgery, and the restoration of a medial constraint (MPFL) is considered to be the most important surgical factor. ${ }^{1,90-92}$

The principle of surgical management with recurrent instability is to address the primary abnormal anatomical factor or interacting factors contributing to the instability, without resulting in excessive abnormal loads on the articular cartilage. However, addressing each risk factor, often with potential complications and unproven long-term side effects on the articular cartilage, is not currently supported by definitive evidence in the literature. It is not always straightforward, and many different operations have been described and various combinations used to address the abnormal anatomical factors. An MPFL or medial stabilisation procedure is typically performed in conjunction with the other bony procedures (Table II). This makes evaluation and comparisons of the literature difficult. An algorithmic approach is commonly recommended (Figures 7-9).

Surgical options include medial repair or reefing, lateral release, MPFL reconstruction, tibial tubercle osteotomy (with medialisation or distalisation), trochleoplasty and derotational osteotomies.

\section{Lateral release}

An isolated lateral retinacular release is no longer recommended and has shown to be ineffective in the treatment of patellar instability. It may be indicated in combination when there is pathologic retinacular tightness, i.e. when manual correction to neutral is not possible on physical examination (and not only evidenced by excessive patella tilt on imaging). ${ }^{2,93-96}$ Excessive lateral release may be complicated by medial instability. ${ }^{95}$

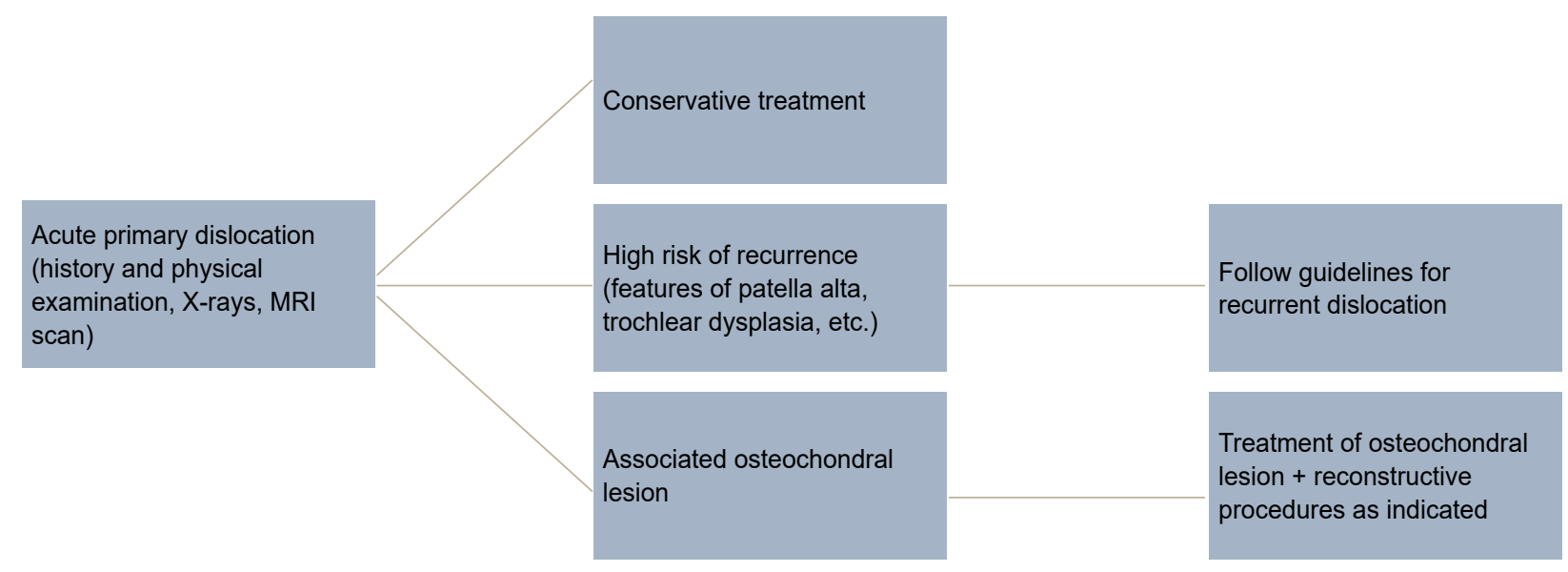

Figure 7. Suggested management algorithm for first episode patellofemoral dislocations 


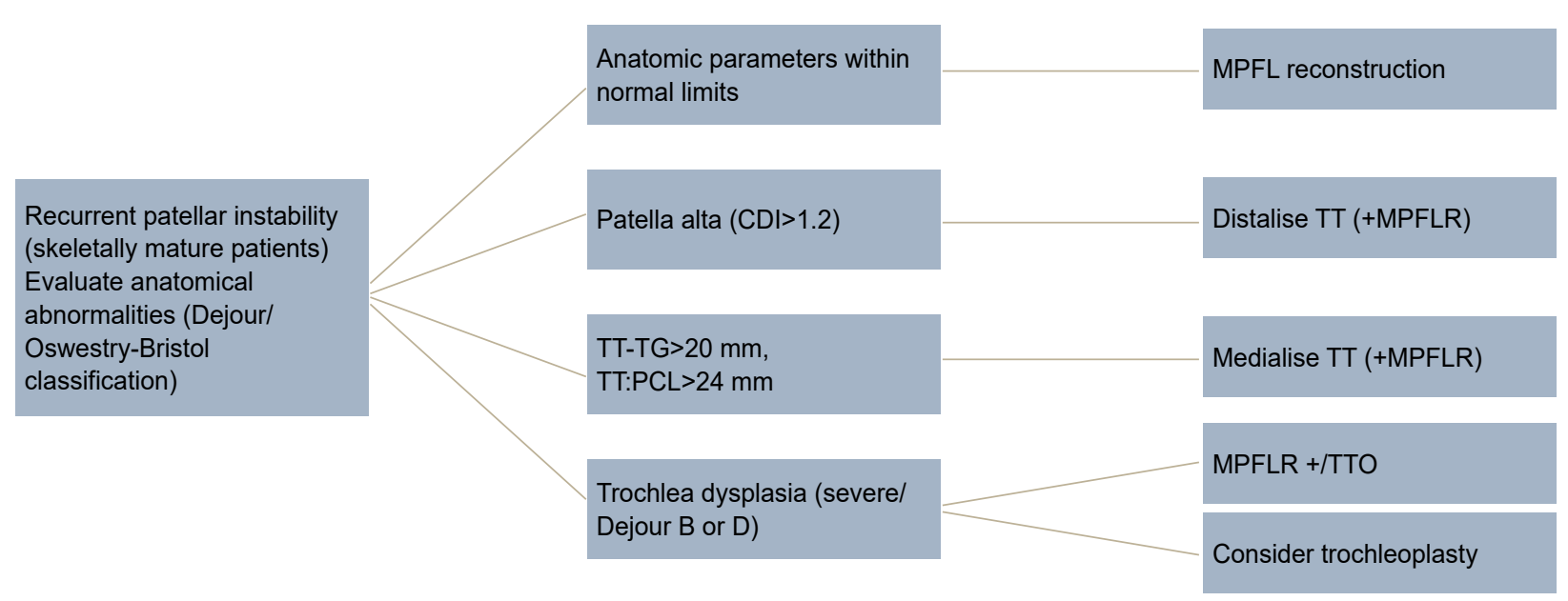

Figure 8. Suggested management algorithm for recurrent patellofemoral instability in skeletally mature patients

\section{Medial repair and imbrication}

Repair may be considered in certain rare cases without evidence of dysplasia, malalignment and hypermobility, and with a clearly identifiable femoral avulsion injury. There is a high reported rate of recurrent instability due to the difficulty in visualising the exact location of the MPFL injury. ${ }^{65,71,97-99}$ In the paediatric and adolescent populations, medial imbrication has evolved from Insall's extensive technique to a multitude of newer less invasive techniques involving medial reefing with or without arthroscopic lateral release, reporting good/excellent results. ${ }^{100}$ These techniques avoid injury to the physis and do not need soft tissue grafts.

\section{MPFL reconstruction}

The MPFL is the most important restraint to lateral patella displacement from $0-30^{\circ}$ of flexion. ${ }^{90-92}$ It dramatically reduces subjective instability and frank dislocations. ${ }^{101-105}$ It is indicated as an isolated procedure when recurrent instability is present without associated major anatomical abnormalities, i.e. TT-TG distance $<20 \mathrm{~mm}$, normal/mild trochlear dyplasia (Dejour type A), absence of patella alta (Caton-Deschamps index $<1.2$ ), and a patella tilt $<20^{\circ} .{ }^{24,106}$ Various autografts and allografts have been used, e.g. Gracilis tendon. Different patella attachment techniques have been described, e.g. bone tunnels, suture anchors and interference screws. All of these methods approach or exceed the load-to-failure of the native MPFL. ${ }^{107-109}$ There are also many options of fixation to the femur, e.g. docking tunnels with interference screws or anchors.
In a meta-analysis of 1065 MPFL reconstructions in 31 studies, it was found that autograft was better, and double-limbed reconstructions had better outcomes. ${ }^{110}$ The most important aspect is determining the correct anatomic location using anatomic landmarks as well as radiographic parameters ensuring correct graft isometry and reproduction of normal tension during knee range of motion. ${ }^{16,111,112}$ Radiographic parameters which can be used intraoperatively include distal femoral percentage measurements as described by Stephen et al. More commonly, Schottle point is utilised which is $1.3 \mathrm{~mm}$ anterior to the tangent of the posterior femoral cortex, 2.5 $\mathrm{mm}$ distal to the perpendicular of the superior border of the femoral condyle, and immediately proximal to a perpendicular line from the supero-posterior aspect of Blumensaat line (Figure 10). This reproducibly locates the femoral tunnel within a $5 \mathrm{~mm}$ isometric point for fixation. ${ }^{16,111,113}$ Malpositioning can lead to excessive load on the medial patella facet. ${ }^{114}$ Overtensioning can lead to increased patellofemoral contact pressures. ${ }^{115}$ Other complications are patella fracture, loss of motion and arthrofibrosis. ${ }^{116,117}$ The optimal amount of knee flexion to fix the graft has not been definitively determined, but fixation in $>60^{\circ}$ will exacerbate any malpositioned femoral fixation. ${ }^{118}$ Thaunat and Erasmus introduced the concept of favourable anisometry, or graft isometry from $0-30^{\circ}$ flexion..$^{119}$ Graft tension can be measured intraoperatively but should be compared to the contralateral knee. Stephen et al. ${ }^{113}$ reported that only $2 \mathrm{~N}$ of graft tension accurately restored contact pressure and patellar tracking. Koh and Stewart suggested that there should be

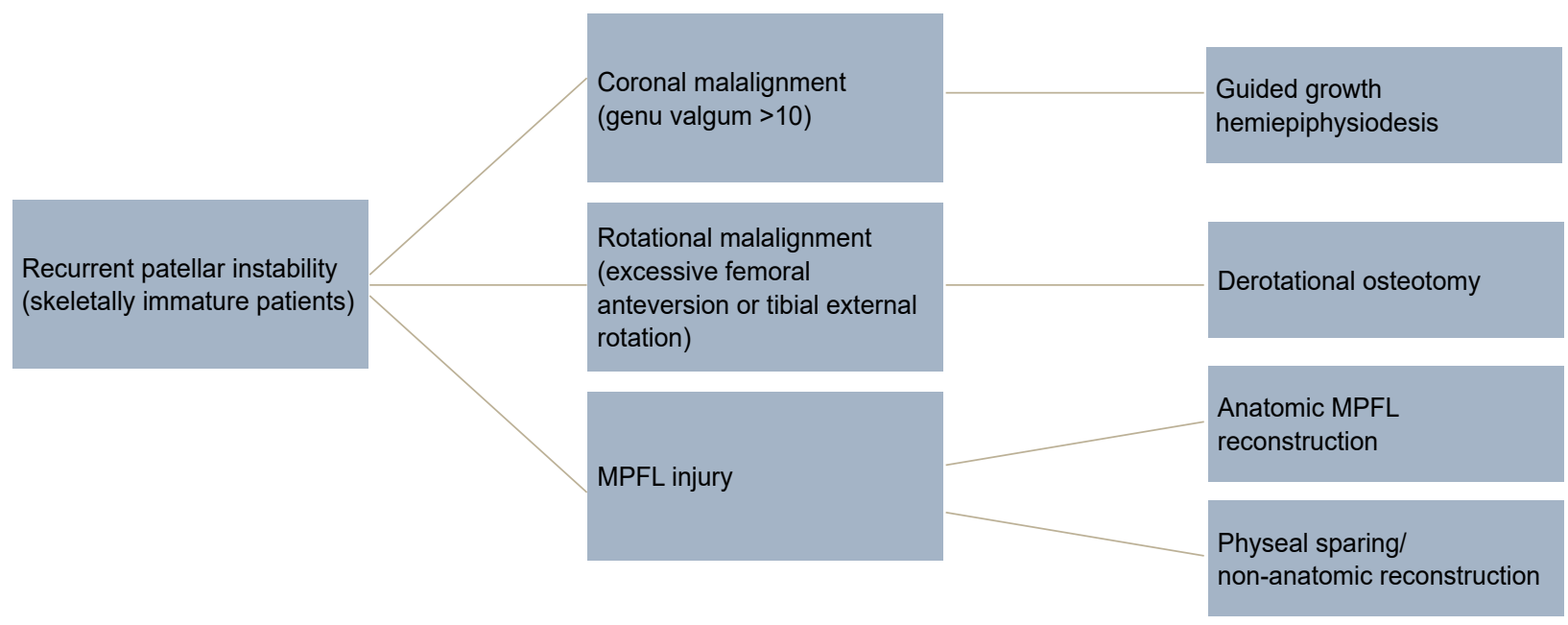

Figure 9. Suggested management algorithm for recurrent patellofemoral instability in skeletally immature patients 


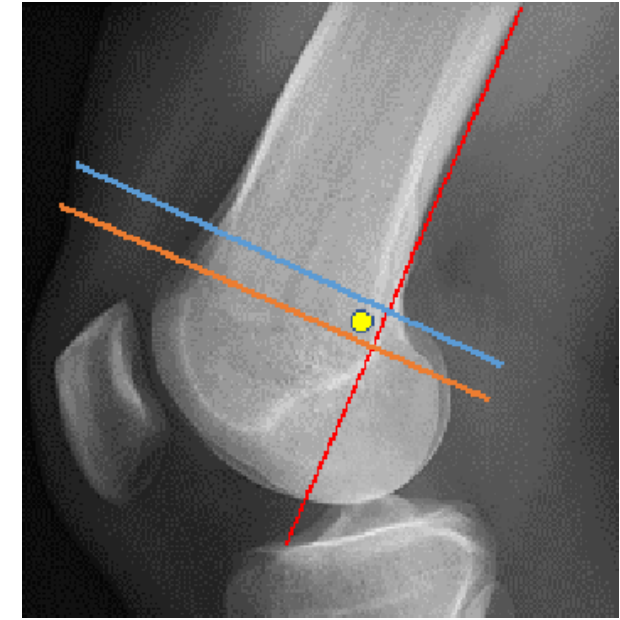

Figure 10. Schottle point determined by line along posterior cortex (red line), then perpendicular lines through origin of medial condyle and Blumensaat line (blue and orange lines respectively). Insertion point 1.3 $\mathrm{mm}$ anterior to red line and $2.5 \mathrm{~mm}$ distal to blue line (yellow dot)

(Produced by author ML Grundill)

$1 \mathrm{~cm}$ of lateral translation in full extension or the equivalent of two quadrants lateral deviation with a firm endpoint. ${ }^{120}$ Placement of the femoral tunnel too proximally will result in a graft that is too tight in flexion, and too distal will make it too loose in flexion. ${ }^{121}$ Overall, MPFL reconstruction results in appropriate patellar stability with $<10 \%$ redislocation rates, and numerous studies show good or excellent clinical outcomes. ${ }^{119,122-128}$ This is a technically demanding procedure with complication rates as high as $26 \%$, and up to $15.8 \%$ reoperation rate. ${ }^{116,129}$

\section{Distal realignment procedures/tibial tubercle transfer}

Osteotomies for patellofemoral instability fall into three groups: ${ }^{130,131}$ 1. Fulkerson anteromedialisation (AMZ) of the tibial tubercle

2. Medial tibial tubercle transfer as described by Emslie-Trillat et al. 3. Distalisation using a step-cut or feathered distal cut

The Fulkerson AMZ, which was originally described for patella chondrosis, is most commonly used as it can unload the distal and lateral articular cartilage and improve patella maltracking. The oblique osteotomy allows customising the individual deformity. A long, hinged osteotomy fixed with a minimum of two screws with flat headed low-profile screws is preferred. ${ }^{132}$ The preferred magnitude of medialisation varies; however, most researchers agree that the postoperative TT-TG goal should be $9-15 \mathrm{~mm} \cdot{ }^{33,133-135}$ When assessing the role of patella alta in the instability, various indices can be used as discussed previously. No absolute cut-off value for increased TT-TG has been defined and the measurements are less than ideally reproducible. ${ }^{128}$ Indications for distal realignment include a TT-TG $>15-20 \mathrm{~mm}^{52}$ and a Caton-Deschamps $>1.2-1.4 .^{24,136-138}$ An elevated TT-PCL or a patellotrochlear index $(\mathrm{PTI})<15-20 \% \quad(<0.32)$ or sagittal patellofemoral engagement (SPE) $<0.45$ can also assist decision-making. ${ }^{24,54}$ Distalisation of roughly $6-7 \mathrm{~mm}$ using a feathered shingle can be used if $\mathrm{CDI}>1.2$, and if $\mathrm{CDI}>1.4$, a step-cut TTO is performed. ${ }^{24,54,132}$ Distalisation is indicated for patellar instability in the setting of patella alta. This may be combined with an AMZ in selected cases. Isolated anteriorisation as described by Maquet is not indicated for patellofemoral instability. ${ }^{139}$

Isolating clinical outcomes is difficult because most studies have cohorts of patients with multiple contributory factors and have required concomitant procedures, but distal realignment procedures have been shown to result in low redislocation rates ${ }^{62,135,140-142}$ and patient satisfaction has been rated to be good or excellent for
63-90\%. ${ }^{62,142-144}$ The overall risk of complications has been found to be between $4.6 \%$ and $7.4 \%$, although removal of hardware is required in $36-50 \%$ of cases. ${ }^{134,145}$ In a recent systematic review of outcomes after concomitant MPFL and tibial tubercle transfer (TTT), these procedures were found to be effective in the setting of malalignment. ${ }^{146}$ Consensus groups are hesitant to universally recommend the use of medialisation or patellar instability. ${ }^{1,147-149}$

\section{Trochleoplasty}

The aim is to create a recentralised groove, correcting the trochlear depth abnormality and thus stabilising the patella by an improved entrance into the trochlear groove. ${ }^{150}$ Several types of trochleoplasty have been described including a lateral facet-elevating Albeetype; 151 a sulcus-deepening trochleoplasty (described by Masse and later modified by Dejour ${ }^{35,150}$ and Bereiter ${ }^{152}$ ); and a proximal recession wedge trochleoplasty described by Goutallier. ${ }^{153}$ According to Dejour, trochleoplasty is indicated for severe trochlear dysplasia (Dejour types B and D). ${ }^{35}$ and according to the OswestryBristol classification, indications are severe dysplasia as indicated by a convex/domed trochlea on MRI. ${ }^{37}$ Contraindications include an open physis and patellofemoral arthritis. Most cases will also need an MPFL reconstruction, but the need for a TTT should be decided on a case-by-case basis. ${ }^{149,154}$ It is a technically challenging procedure and should be limited to surgeons experienced and trained in its use.

Trochleoplasty is often not performed, despite good basic science and clinical data, as there are concerns regarding the long-term effects on articular cartilage, arthrofibrosis (2-46\%) and arthritis. ${ }^{1,151,155,156}$ The failure rates with recurrent instability are varied $(0.8-10.5 \%)$ and the reoperation rates are high $(14-25 \%) .{ }^{157-160}$ In a systematic review by Longo et al., $40 \%$ of patients who had a trochleoplasty had complications, including increased pain in $11 \%$ of cases; $6.7 \%$ reduction in range of motion; and $12 \%$ developed $\mathrm{OA} .{ }^{157}$ Clinical outcome reviews describe a reduction in patella apprehension of $80 \%$, and improved Kujala scores postoperatively, with up to $92 \%$ patient satisfaction. ${ }^{157,158,161}$

\section{Skeletally immature patients}

In the skeletally immature population there is an especially high incidence in females aged between 10 and 17 years. ${ }^{5,162,163}$ The child typically presents with vague symptoms, and a high index of suspicion should be maintained. Management is usually nonoperative except in cases of large displaced osteochondral fragments; however, recent trends suggest acute surgical intervention may be warranted in certain situations with high risk factors for recurrence. ${ }^{164}$ Hinton and Sharma classified adolescent primary dislocators into two groups to guide decision-making (Table III). There is a shift from non-anatomic procedures to techniques that restore normal anatomy, and special attention is focused on avoiding physeal injury. No evidence of growth

Table III: Classification of adolescent primary dislocators

\begin{tabular}{ll} 
LAACS & TONES \\
\hline Laxity and younger & Traumatic/sports-related \\
\hline Atraumatic and chronic & Older age \\
\hline Abnormal patellofemoral & Normal alignment and \\
architecture & architecture \\
\hline Contralateral side & Equal sex distribution \\
\hline & Single occurrence \\
\hline Conservative management & MRI and consider early \\
& stabilisation
\end{tabular}

(Adapted from Hinton RY, Sharma KM. Patellar instability in childhood and adolescence. In: Insall JN, Scott WN, editors. Surgery of the knee. 4th ed. London: Churchill Livingstone; 2006) 
disturbance was found when using physeal-sparing techniques. ${ }^{165}$ An important consideration is that the femoral origin of the MPFL is located 5-6 mm distal to the open physis in the young patient. ${ }^{166,167}$ Anatomic fixation of the epiphyseal femoral origin is important to avoid proximalisation of the MPFL insertion and thus tightening of the ligament during growth. ${ }^{168}$

Patellar stabilisation procedures are grouped into two main categories: proximal realignment and distal realignment procedures. Distal soft-tissue procedures or proximal-only procedures should be used when the tibial physis is open. Medial imbrication has evolved from Insall's extensive technique to a multitude of newer, less-invasive techniques involving medial reefing with or without arthroscopic lateral release, reporting good/excellent results. ${ }^{100}$ An MPFL reconstruction as performed in adults has become the treatment of choice in most active adolescent patients. ${ }^{169}$

Many other MPFLRs have been described using different graft options such as:

1. Semitendinosus autograft with an MCL pulley ${ }^{170}$

2. Autologous quadriceps tendon ${ }^{171}$

3. Adductor magnus tendon ${ }^{172}$

4. Semitendinosus around an adductor sling ${ }^{173}$

Combined proximal and distal procedures like the modified Galleazi, Grammont and Roux-Goldthwait have also been described, the details of which are beyond the scope of this article. ${ }^{169,174-177}$

In summary, when performing an MPFLR in skeletally immature patients, Ries and Bollier recommends wrapping the free ends of the graft around the adductor tendon in younger patients, and using fluoroscopy while creating the femoral epiphyseal tunnel in older adolescents. Distal realignment can be achieved with soft tissue procedures but TTT should only be considered in skeletally mature patients. ${ }^{100}$

\section{Conclusion}

Patellofemoral dislocation occurs in young, active patients and can lead to recurrent instability unless it is appropriately managed. Nonoperative management is still the mainstay of treatment for most first-episode dislocations, unless there is associated osteochondral pathology requiring surgical intervention. Using this approach approximately $40 \%$ of patients will experience recurrent instability and require surgical intervention. Despite abundant evidence on the topic, there is no consensus on which surgical approach is most appropriate for recurrent dislocation. A reasonable approach, supported by evidence, includes performing an MPFL reconstruction in most cases of recurrent instability, with additional procedures (e.g. TTO/trochleoplasty) tailored to the individual as indicated. This serves to maximise the benefit to the patient, while limiting the risk of complications.

\section{Ethics statement}

The authors declare that this submission is in accordance with the principles laid down by the Responsible Research Publication Position Statements as developed at the 2nd World Conference on research integrity in Singapore, 2010. Ethical approval for this study was not obtained - review article.

\section{Declaration}

The authors declare authorship of this article and that they have followed sound scientific research practice. This research is original and does not transgress plagiarism policies.

\section{Author contributions}

Both authors contributed to the conception and design of the work, literature review, analysis, drafting of the work; and final approval of the version to be published.

\section{ORCID}

Garrett BR (iD) https://orcid.org/0000-0002-0478-8136 Grundill ML (D) https://orcid.org/0000-0002-4308-4051

\section{References}

1. Post WR, Fithian DC. Patellofemoral instability: a consensus statement from the AOSSM/PFF Patellofemoral Instability Workshop. Orthop J Sport Med. 2018;6(1):1-5

2. Fithian DC, Paxton EW, Stone M Lou, et al. Epidemiology and natural history of acute patellar dislocation. Am J Sports Med. 2004;32(5):1114-21.

3. Hsiao M, Owens BD, Burks R, Sturdivant RX, Cameron KL. Incidence of acute traumatic patellar dislocation among active-duty United States military service members. Am J Sports Med. 2010 Oct;38(10):1997-2004.

4. Steensen RN, Bentley JC, Trinh TQ, Backes JR, Wiltfong RE. The prevalence and combined prevalences of anatomic factors associated with recurrent patellar dislocation: A magnetic resonance imaging study. Am J Sports Med. 2015;43(4):921-27.

5. Atkin DM, Fithian DC, Marangi KS, et al. Characteristics of patients with primary acute lateral patellar dislocation and their recovery within the first 6 months of injury. Am J Sports Med. 2000;28(4):472-79.

6. Smith TO, Donell S, Song F, Hing CB. Surgical versus non-surgical interventions for treating patellar dislocation. Cochrane Database Syst Rev. 2015;(2):CD008106. https://doi.org//10.1002/14651858.CD008106.pub3.

7. Magnussen RA, Verlage $M$, Stock E, et al. Primary patellar dislocations without surgical stabilization or recurrence: how well are these patients really doing? Knee Surg Sports Traumatol Arthrosc. 2017 Aug;25(8):2352-56.

8. Dejour H, Walch G, Nove-Josserand L, Guier C. Factors of patellar instability: An anatomic radiographic study. Knee Surgery, Sport Traumatol Arthrosc. 1994;2(1):19-26. https://doi.org/10.1007/BF01552649.

9. Ellera Gomes JL. Medial patellofemoral ligament reconstruction for recurrent dislocation of the patella: a preliminary report. Arthrosc J Arthrosc Relat Surg. 1992;8(3):335-40.

10. Parikh SN, Lykissas MG, Gkiatas I. Predicting risk of recurrent patellar dislocation. Curr Rev Musculoskelet Med. 2018;11(2):253-60.

11. Subramanian $P$, Patel R. Patellofemoral instability: an overview. Orthop Trauma. 2019;33(2):119-26. https://doi.org/10.1016/j.mporth.2019.01.007.

12. Liu JN, Brady JM, Kalbian IL, et al. Clinical outcomes after isolated medial patellofemoral ligament reconstruction for patellar instability among patients with trochlear dysplasia. Am J Sports Med. 2018 Mar;46(4):883-89.

13. Sillanpää $P$, Mattila VM, livonen $T$, Visuri $T$, Pihlajamäki $H$. Incidence and risk factors of acute traumatic primary patellar dislocation. Med Sci Sports Exerc. 2008 Apr;40(4):606-11.

14. LaPrade MD, Kallenbach SL, Aman ZS, et al. Biomechanical evaluation of the medial stabilizers of the patella. Am J Sports Med. 2018;46(7):1575-82.

15. Amis AA, Firer P, Mountney J, Senavongse W, Thomas NP. Anatomy and biomechanics of the medial patellofemoral ligament. Knee. 2003 Sep;10(3):215-20.

16. Stephen JM, Lumpaopong P, Deehan DJ, Kader D, Amis AA. The medial patellofemoral ligament: Location of femoral attachment and length change patterns resulting from anatomic and nonanatomic attachments. Am J Sports Med. 2012;40(8):1871-79.

17. LaPrade RF, Engebretsen AH, Ly TV, et al. The anatomy of the medial part of the knee. J Bone Jt Surg Am. 2007;89(9):2000-10. https://doi.org/10.2106/ jbjs.f.01176.

18. Glard Y, Jouve J-L, Garron E, et al. Anatomic study of femoral patellar groove in fetus. J Pediatr Orthop. 2005;25(3):305-308.

19. Nietosvaara $Y$, Aalto K, Kallio PE. Acute patellar dislocation in children: incidence and associated osteochondral fractures. J Pediatr Orthop. 1994;14(4):513-15.

20. Farahmand F, Senavongse W, Amis AA. Quantitative study of the quadriceps muscles and trochlear groove geometry related to instability of the patellofemoral joint. J Orthop Res. 1998;16(1):136-43.

21. James S, Bates B, Ostering L. Injuries to runners. Class Pap Orthop. 2014;(1):205-207.

22. Brattström H. Patella alta in non-dislocating knee joints. Acta Orthop Scand 1970;41(5):578-88.

23. France $L$, Nester $C$. Effect of errors in the identification of anatomical landmarks on the accuracy of $Q$ angle values. Clin Biomech (Bristol, Avon). 2001 Oct;16(8):710-13.

24. Biedert RM, Albrecht $S$. The patellotrochlear index: a new index for assessing patellar height. Knee Surg Sports Traumatol Arthrosc. 2006 Aug;14(8):707-12.

25. Cooney AD, Kazi Z, Caplan N, et al. The relationship between quadriceps angle and tibial tuberosity-trochlear groove distance in patients with patellar instability. Knee Surg Sports Traumatol Arthrosc. 2012 Dec;20(12):2399-404.

26. Guerra JP, Arnold MJ, Gajdosik RL. Q angle: effects of isometric quadriceps contraction and body position. J Orthop Sports Phys Ther. 1994 Apr;19(4):200-204.

27. Abbasi D, May MM, Wall EJ, et al. MRI findings in adolescent patients with acute traumatic knee hemarthrosis. J Pediatr Orthop. 2012 Dec;32(8):760-64. 
28. Post WR. Clinical evaluation of patients with patellofemoral disorders. Arthrosc J Arthrosc Relat Surg. 1999;15(8):841-51

29. Lester JD, Watson JN, Hutchinson MR. Physical examination of the patellofemoral joint. Clin Sports Med. 2014;33(3):403-12. https://doi. org/10.1016/j.csm.2014.03.002.

30. Ahmad CS, McCarthy M, Gomez JA, Shubin Stein BE. The moving patellar apprehension test for lateral patellar instability. Am J Sports Med. 2009;37(4):791-96

31. Beighton $\mathrm{P}$, Solomon L, Soskolne CL. Articular mobility in an African population. Ann Rheum Dis. 1973;32(5):413-18.

32. Ntagiopoulos PG, Bonin N, Sonnery-Cottet B, et al. The incidence of trochlear dysplasia in anterior cruciate ligament tears. Int Orthop. 2014 Jun;38(6):1269-75.

33. Dejour D, Le Coultre B. Osteotomies in patello-femoral instabilities. Sports Med Arthrosc. 2007;15(1):39-46.

34. Dejour H, Walch G, Neyret P, Adeleine P. [Dysplasia of the femoral trochlea] Rev Chir Orthop Reparatrice Appar Mot. 1990;76(1):45-54.

35. Dejour D, Saggin P. The sulcus deepening trochleoplasty-the Lyon's procedure. Int Orthop. 2010 Feb;34(2):311-16.

36. Remy $\mathrm{F}$, Besson $\mathrm{A}$, Migaud $\mathrm{H}$, et al. [Reproducibility of the radiographic analysis of dysplasia of the femoral trochlea. Intra- and interobserver analysis of 68 knees]. Rev Chir Orthop Reparatrice Appar Mot. 1998 Nov;84(8):728-33.

37. Sharma N, Brown A, Bouras T, et al. The Oswestry-Bristol classification: A new classification system for trochlear dysplasia. Bone Jt J. 2020;102(1):102-107.

38. Merchant AC, Mercer RL, Jacobsen RH, Cool CR. Roentgenographic analysis of patellofemoral congruence. J Bone Joint Surg Am. 1974 Oct;56(7):1391-96.

39. Blackburne JS, Peel TE. A new method of measuring patellar height. J Bone Jt Surg - Ser B. 1977;59(2):241-45

40. Grelsamer RP, Meadows S. The modified Insall-Salvati ratio for assessment of patellar height. Clin Orthop Relat Res. 1992 Sep;(282):170-76.

41. Koshino T, Sugimoto K. New measurement of patellar height in the knees of children using the epiphyseal line midpoint. J Pediatr Orthop. 1989;9(2):216-18.

42. Merchant AC. Patellofemoral imaging. Clin Orthop Relat Res. 2001;(389):15-21.

43. Caton J. [Method of measuring the height of the patella]. Acta Orthop Belg 1989;55(3):385-86

44. Aparicio G, Abril JC, Albiñana J, Rodríguez-Salvanés F. Patellar height ratios in children: an interobserver study of three methods. J Pediatr Orthop B. 1999 Jan;8(1):29-32.

45. Dickens AJ, Morrell NT, Doering A, et al. Tibial tubercle-trochlear groove distance: defining normal in a pediatric population. J Bone Joint Surg Am. 2014 Feb;96(4):318-24

46. Tanaka MJ, Elias JJ, Williams AA et al. Correlation between changes in tibial tuberosity-trochlear groove distance and patellar position during active knee extension on dynamic kinematic computed tomographic imaging. Arthroscopy. 2015;31(9):1748-55.

47. Sanders TG, Morrison WB, Singleton BA, et al. Medial patellofemoral ligament injury following acute transient dislocation of the patella: MR findings with surgical correlation in 14 patients. J Comput Assist Tomogr. 2001;25(6):957-62.

48. Nomura E, Inoue M. Second-look arthroscopy of cartilage changes of the patellofemoral joint, especially the patella, following acute and recurrent patellar dislocation. Osteoarthr Cartil. 2005 Nov;13(11):1029-36.

49. Nomura E, Inoue M. Cartilage lesions of the patella in recurrent patellar dislocation. Am J Sports Med. 2004 Mar;32(2):498-502

50. Elias DA, White LM, Fithian DC. Acute lateral patellar dislocation at MR imaging: injury patterns of medial patellar soft-tissue restraints and osteochondral injuries of the inferomedial patella. Radiology. 2002 Dec;225(3):736-43.

51. Camp CL, Stuart MJ, Krych AJ, et al. CT and MRI measurements of tibial tubercle-trochlear groove distances are not equivalent in patients with patellar instability. Am J Sports Med. 2013 Aug;41(8):1835-40.

52. Anley CM, Morris GV, Saithna A, et al. Defining the role of the tibial tubercletrochlear groove and tibial tubercle-posterior cruciate ligament distances in the work-up of patients with patellofemoral disorders. Am J Sports Med. 2015 Jun;43(6):1348-53.

53. Seitlinger G, Scheurecker G, Högler R, et al. Tibial tubercle-posterio cruciate ligament distance: a new measurement to define the position of the tibial tubercle in patients with patellar dislocation. Am J Sports Med. 2012 May;40(5):1119-25.

54. Dejour D, Ferrua P, Ntagiopoulos PG, et al. The introduction of a new MRI index to evaluate sagittal patellofemoral engagement. Orthop Traumatol Surg Res. 2013 Dec;99(8 Suppl):S391-8.

55. Guilbert S, Chassaing V, Radier C, et al. Axial MRI index of patellar engagement: a new method to assess patellar instability. Orthop Traumatol Surg Res. 2013 Dec;99(8 Suppl):S399-405
56. Askenberger M, Janarv PM, Finnbogason T, Arendt EA. Morphology and anatomic patellar instability risk factors in first-time traumatic lateral patellar dislocations. Am J Sports Med. 2017;45(1):50-58.

57. Nelitz M, Lippacher S, Reichel H, Dornacher D. Evaluation of trochlear dysplasia using MRI: correlation between the classification system of Dejour and objective parameters of trochlear dysplasia. Knee Surg Sports Traumatol Arthrosc. 2014 Jan;22(1):120-27

58. Lewallen L, McIntosh A, Dahm D. First-time patellofemoral dislocation: risk factors for recurrent instability. J Knee Surg. 2015 Aug;28(4):303-309.

59. Fitzpatrick CK, Steensen RN, Tumuluri A, et al. Computational analysis of factors contributing to patellar dislocation. J Orthop Res Off Publ Orthop Res Soc. 2016 Mar;34(3):444-53.

60. Hiemstra LA, Kerslake S, Lafave M. Assessment of demographic and pathoanatomic risk factors in recurrent patellofemoral instability. Knee Surg Sports Traumatol Arthrosc. 2017 Dec;25(12):3849-55

61. Balcarek $\mathrm{P}$, Oberthür $\mathrm{S}$, Hopfensitz $\mathrm{S}$, et al. Which patellae are likely to redislocate? Knee Surg Sports Traumatol Arthrosc. 2014 Oct;22(10):2308-14.

62. Garth J, Dichristina DG, Holt G. Delayed proximal repair and distal realignment after patellar dislocation. Clin Orthop Relat Res. 2000;26(377):132-44.

63. Hawkins RJ, Bell RH, Anisette G. Acute patellar dislocations. The natural history. Am J Sports Med [Internet]. 1986;14(2):117-20. Available from: http:// www.ncbi.nlm.nih.gov/pubmed/3717480.

64. Mehta VM, Inoue M, Nomura E, Fithian DC. An algorithm guiding the evaluation and treatment of acute primary patellar dislocations. Sports Med Arthrosc Rev. 2007;15(2):78-81.

65. Sillanpää PJ, Peltola E, Mattila VM, et al. Femoral avulsion of the medial patellofemoral ligament after primary traumatic patellar dislocation predicts subsequent instability in men: A mean 7-year nonoperative follow-up study. Am J Sports Med. 2009;37(8):1513-21.

66. Nikku R, Nietosvaara $Y$, Kallio PE, et al. Operative versus closed treatment of primary dislocation of the patella. Similar 2-year results in 125 randomized patients. Acta Orthop Scand. 1997;68(5):419-23.

67. Camanho GL, Viegas A de C, Bitar AC, et al. Conservative versus surgical treatment for repair of the medial patellofemoral ligament in acute dislocations of the patella. Arthrosc - J Arthrosc Relat Surg. 2009;25(6):620-25. https://doi. org/10.1016/j.arthro.2008.12.005.

68. Bitar AC, Demange MK, D'Elia CO, Camanho GL. Traumatic patellar dislocation: Nonoperative treatment compared with MPFL reconstruction using patellar tendon. Am J Sports Med. 2012;40(1):114-22.

69. Petri M, Liodakis E, Hofmeister M, et al. Operative vs conservative treatment of traumatic patellar dislocation: Results of a prospective randomized controlled clinical trial. Arch Orthop Trauma Surg. 2013;133(2):209-13.

70. Xing $X$, Shi H, Feng S. Does surgical treatment produce better outcomes than conservative treatment for acute primary patellar dislocations? A meta-analysis of 10 randomized controlled trials. J Orthop Surg Res. 2020;15(1):1-9.

71. Palmu S, Kallio PE, Donell ST, et al. Acute patellar dislocation in children and adolescents: A randomized clinical trial. J Bone Jt Surg - Ser A. 2008;90(3):463-70.

72. Apostolovic M, Vukomanovic B, Slavkovic N, et al. Acute patellar dislocation in adolescents: Operative versus nonoperative treatment. Int Orthop. 2011;35(10):1483-87.

73. Gillespie H. Update on the management of patellar instability. Curr Sports Med Rep. 2012;11(5):226-31.

74. Buchner M, Baudendistel B, Sabo D, Schmitt $\mathrm{H}$. Acute traumatic primary patellar dislocation long-term results comparing conservative and surgical treatment conclusions: even with a focus on acute traumatic etiology and. Clin J Sport Med [Internet]. 2005;15(2):62-66. Available from: https://insights.ovid. com/pubmed?pmid=15782048.

75. Duthon VB. Acute traumatic patellar dislocation. Orthop Traumatol Surg Res. 2015;101(1):S59-S67. https://doi.org/10.1016/j.otsr.2014.12.001.

76. Mäenpää $\mathrm{H}$, Lehto MUK. Patellar dislocation. The long-term results of nonoperative management in 100 patients. Am J Sports Med. 1997;25(2):213-17.

77. Armstrong BM, Hall M, Crawfurd E, Smith TO. A feasibility study for a pragmatic randomised controlled trial comparing cast immobilisation versus no immobilisation for patients following first-time patellar dislocation. Knee. 2012;19(5):696-702. https://doi.org/10.1016/j.knee.2011.08.004.

78. Rood A, Boons H, Ploegmakers J, et al. Tape versus cast for non-operative treatment of primary patellar dislocation: A randomized controlled trial. Arch Orthop Trauma Surg. 2012;132(8):1199-203.

79. Stensdotter AK, Hodges PW, Mellor R, Sundelin G, Häger-Ross C. Quadriceps activation in closed and in open kinetic chain exercise. Med Sci Sports Exerc. 2003;35(12):2043-47.

80. Kaewkongnok B, Bøvling A, Milandt N, et al. Does different duration of non-operative immobilization have an effect on the redislocation rate of 
primary patellar dislocation? A retrospective multicenter cohort study. Knee. 2018;25(1):51-58. https://doi.org/10.1016/j.knee.2017.10.002.

81. Becher C, Schumacher T, Fleischer B, et al. The effects of a dynamic patellar realignment brace on disease determinants for patellofemoral instability in the upright weight-bearing condition. J Orthop Surg Res. 2015;10(1):1-8. https:// doi.org/10.1186/s13018-015-0265-x.

82. Colvin AC, West R V. Patellar instability. J Bone Jt Surg - Ser A. 2008;90(12):2751-62

83. Khormaee S, Kramer DE, Yen YM, Heyworth BE. Evaluation and management of patellar instability in pediatric and adolescent athletes. Sports Health. 2015;7(2):115-23.

84. Moiz M, Smith N, Smith TO, et al. Clinical outcomes after the nonoperative management of lateral patellar dislocations: a systematic review. Orthop J Sport Med. 2018;6(6):1-17.

85. Cowan SM, Bennell KL, Hodges PW. Therapeutic patellar taping changes the timing of vasti muscle activation in people with patellofemoral pain syndrome. Clin J Sport Med. 2002;12(6):339-47.

86. McConnell J. Rehabilitation and nonoperative treatment of patellar instability Sports Med Arthrosc. 2007;15(2):95-104.

87. Ménétrey J, Putman S, Gard S. Return to sport after patellar dislocation or following surgery for patellofemoral instability. Knee Surg Sports Traumatol Arthrosc. 2014;22(10):2320-26.

88. Respizzi S, Cavallin R. First patellar dislocation: From conservative treatment to return to sport. Joints. 2014;2(3):141-45.

89. Parikh SN, Nathan ST, Wall EJ, Eismann EA. Complications of medial patellofemoral ligament reconstruction in young patients. Am J Sports Med. 2013;41(5):1030-38.

90. Desio SM, Burks RT, Bachus KN. Soft tissue restraints to lateral patellar translation in the human knee. Am J Sports Med. 1998;26(1):59-65.

91. Hautamaa PV, Fithian DC, Kaufman KR, et al. Medial soft tissue restraints in lateral pateliar instability and repair. Clin Orthop Relat Res. 1998;(349):174-82.

92. Conlan T, Garth WP, Lemons JE. Evaluation of the medial soft-tissue restraints of the extensor mechanism of the knee. J Bone Joint Surg Am. 1993;75(5):682-93

93. Kolowich PA, Paulos LE, Rosenberg TD, Farnsworth S. Lateral release of the patella: Indications and contraindications. Am J Sports Med. Jul-Aug 1990;18(4):359-65. PMID: 2403183

94. Lattermann C, Toth J, Bach BR. The role of lateral retinacular release in the treatment of patellar instability. Sports Med Arthrosc. 2007;15(2):57-60.

95. Christoforakis J, Bull AMJ, Strachan RK, et al. Effects of lateral retinacular release on the lateral stability of the patella. Knee Surg Sports Traumatol Arthrosc. 2006;14(3):273-77.

96. Hughston JC, Deese M. Medial subluxation of the patella as a complication of lateral retinacular release. Am J Sports Med. 1988;16(4):383-88.

97. Matic GT, Magnussen RA, Kolovich GP, Flanigan DC. Return to activity after medial patellofemoral ligament repair or reconstruction. Arthrosc - J Arthrosc Relat Surg. 2014;30(8):1018-25. https://doi.org/10.1016/j.arthro.2014.02.044

98. Weber-Spickschen TS, Spang J, Kohn L, et al. The relationship between trochlear dysplasia and medial patellofemoral ligament rupture location after patellar dislocation: An MRI evaluation. Knee. 2011;18(3):185-88. https://doi. org/10.1016/j.knee.2010.04.002

99. Nomura E. Classification of lesions of the medial patello-femoral ligament in patellar dislocation. Int Orthop. 1999;23(5):260-63

100. Ries Z, Bollier M. Patellofemoral instability in active adolescents. J Knee Surg. 2015;28(4):265-77

101. Astur DC, Gouveia GB, Borges JH de S, et al. Medial patellofemoral ligament reconstruction: a longitudinal study comparison of 2 techniques with 2 and 5-years follow-up. Open Orthop J. 2015;9(1):198-203.

102. Baer MR, Macalena JA. Medial patellofemoral ligament reconstruction: Patient selection and perspectives. Orthop Res Rev. 2017;9:83-91.

103. Feller JA, Richmond AK, Wasiak J. Medial patellofemoral ligament reconstruction as an isolated or combined procedure for recurrent patellar instability. Knee Surgery, Sport Traumatol Arthrosc. 2014;22(10):2470-76.

104. Panni AS, Alam M, Cerciello S, et al. Medial patellofemoral ligament reconstruction with a divergent patellar transverse 2-tunnel technique. Am J Sports Med. 2011;39(12):2647-55

105. Matthews JJ, Schranz P. Reconstruction of the medial patellofemoral ligament using a longitudinal patellar tunnel technique. Int Orthop. 2010;34(8):1321-25.

106. Hopper GP, Leach WJ, Rooney BP, et al. Does degree of trochlear dysplasia and position of femoral tunnel influence outcome after medial patellofemoral ligament reconstruction? Am J Sports Med. 2014;42(3):716-22.

107. Russ SD, Tompkins M, Nuckley D, Macalena J. Biomechanical comparison of patellar fixation techniques in medial patellofemoral ligament reconstruction. Am J Sports Med. 2015;43(1):195-99.
108. Mountney J, Senavongse W, Amis AA, Thomas NP. Tensile strength of the medial patellofemoral ligament before and after repair or reconstruction. $J$ Bone Jt Surg - Ser B. 2005;87(1):36-40.

109. Russo F, Doan J, Chase DC, et al. Medial patellofemoral ligament reconstruction: fixation technique biomechanics. J Knee Surg. 2016;29(4):303-309

110. Weinberger JM, Fabricant PD, Taylor SA, et al. Influence of graft source and configuration on revision rate and patient-reported outcomes after MPFL reconstruction: a systematic review and meta-analysis. Knee Surg Sports Traumatol Arthrosc. 2017;25(8):2511-19.

111. Schöttle PB, Schmeling A, Rosenstiel N, Weiler A. Radiographic landmarks for femoral tunnel placement in medial patellofemoral ligament reconstruction. Am J Sports Med. 2007;35(5):801-804.

112. Davis DK, Fithian DC. Techniques of medial retinacular repair and reconstruction. Clin Orthop Relat Res. 2002;(402):38-52.

113. Stephen JM, Kaider $D$, Lumpaopong $P$, et al. The effect of femoral tunnel position and graft tension on patellar contact mechanics and kinematics after medial patellofemoral ligament reconstruction. Am J Sports Med. 2014;42(2):364-72.

114. Elias JJ, Cosgarea AJ. Technical errors during medial patellofemoral ligament reconstruction could overload medial patellofemoral cartilage: A computational analysis. Am J Sports Med. 2006;34(9):1478-85.

115. Beck P, Brown NAT, Greis PE, Burks RT. Patellofemoral contact pressures and lateral patellar translation after medial patellofemoral ligament reconstruction. Am J Sports Med. 2007;35(9):1557-63.

116. Shah JN, Howard JS, Flanigan DC, et al. A systematic review of complications and failures associated with medial patellofemoral ligament reconstruction for recurrent patellar dislocation. Am J Sports Med. 2012;40(8):1916-23.

117. Tanaka MJ, Bollier MJ, Andrish JT, et al. Complications of medial patellofemoral ligament reconstruction: Common technical errors and factors for success AAOS exhibit selection. J Bone Jt Surg - Ser A. 2012;94(12):1-8.

118. Tyrrell Burrus M, Werner BC, Conte EJ, et al. Troubleshooting the femoral attachment during medial patellofemoral ligament reconstruction: Location, location, location. Orthop J Sport Med. 2015;3(1):1-8.

119. Thaunat M, Erasmus PJ. Management of overtight medial patellofemoral ligament reconstruction. Knee Surg Sports Traumatol Arthrosc. 2009;17(5):480-83.

120. Koh JL, Stewart C. Patellar instability. Orthop Clin North Am. 2015;46(1):14757. https://doi.org/10.1016/j.ocl.2014.09.011.

121. Burrus MT, Werner BC, Cancienne JM, et al. MPFL graft fixation in low degrees of knee flexion minimizes errors made in the femoral location. Knee Surg Sports Traumatol Arthrosc. 2017;25(10):3092-98.

122. Hinterwimmer $S$, Imhoff AB, Minzlaff $P$, et al. Anatomical two-bundle medial patellofemoral ligament reconstruction with hardware-free patellar graft fixation: Technical note and preliminary results. Knee Surg Sports Traumatol Arthrosc. 2013;21(9):2147-54.

123. Song SY, Kim IS, Chang HG, et al. Anatomic medial patellofemoral ligament reconstruction using patellar suture anchor fixation for recurrent patellar instability. Knee Surg Sports Traumatol Arthrosc. 2014;22(10):2431-37.

124. Kita K, Tanaka Y, Toritsuka Y, et al. Factors affecting the outcomes of double-bundle medial patellofemoral ligament reconstruction for recurrent patellar dislocations evaluated by multivariate analysis. Am J Sports Med. 2015;43(12):2988-96.

125. Steiner TM, Torga-Spak R, Teitge RA. Medial patellofemoral ligament reconstruction in patients with lateral patellar instability and trochlear dysplasia. Am J Sports Med. 2006;34(8):1254-61.

126. Watanabe $T$, Muneta $T$, Ikeda $H$, et al. Visual analog scale assessment after medial patellofemoral ligament reconstruction: With or without tibial tubercle transfer. J Orthop Sci. 2008;13(1):32-38.

127. Deie M, Ochi M, Adachi N, et al. Medial patellofemoral ligament reconstruction fixed with a cylindrical bone plug and a grafted semitendinosus tendon at the original femoral site for recurrent patellar dislocation. Am J Sports Med. 2011;39(1):140-45

128. Weber AE, Nathani A, Dines JS, et al. An algorithmic approach to the management of recurrent lateral patellar dislocation. J Bone Jt Surg - Am Vol. 2016;98(5):417-27.

129. Seeley MA, Knesek M, Vanderhave KL. Osteochondral injury after acute patellar dislocation in children and adolescents. J Pediatr Orthop. 2013;33(5):511-18.

130. Fulkerson JP. Anteromedialization of the tibial tuberosity for patellofemoral malalignment. Clin Orthop Relat Res. 1983;177:176-81.

131. Fulkerson JP, Becker GJ, Meaney JA, et al. Anteromedial tibial tubercle transfer without bone graft. Am J Sports Med. 1990;18(5):490-97.

132. Laidlaw MS, Diduch DR. Current concepts in the management of patellar instability. Indian J Orthop. 2017;51(5):493-504. 
133. Camp CL, Stuart MJ, Krych AJ, et al. CT and MRI measurements of tibial tubercle-trochlear groove distances are not equivalent in patients with patellar instability. Am J Sports Med. 2013;41(8):1835-40.

134. Servien E, Verdonk PC, Neyret P. Tibial tuberosity transfer for episodic patellar dislocation. Sports Med Arthrosc. 2007;15(2):61-67.

135. Tecklenburg K, Feller JA, Whitehead TS, et al. Outcome of surgery for recurrent patellar dislocation based on the distance of the tibial tuberosity to the trochlear groove. J Bone Jt Surg - Ser B. 2010;92(10):1376-80.

136. Caton $\mathrm{JH}$, Dejour D. Tibial tubercle osteotomy in patello-femoral instability and in patellar height abnormality. Int Orthop. 2010;34(2 special issue):305-309.

137. Duchman K, Bollier M. Distal realignment: Indications, technique, and results Clin Sports Med. 2014;33(3):517-30. https://doi.org/10.1016/j.csm.2014.03.0 01.

138. Magnussen RA, De Simone V, Lustig S, et al. Treatment of patella alta in patients with episodic patellar dislocation: a systematic review. Knee Surg Sports Traumatol Arthrosc. 2014;22(10):2545-50.

139. Sherman SL, Erickson BJ, Cvetanovich GL, et al. Tibial tuberosity osteotomy: Indications, techniques, and outcomes. Am J Sports Med. 2014;42(8):2006-17.

140. Barber FA, McGarry JE. Elmslie-Trillat procedure for the treatment of recurrent patellar instability. Arthrosc - J Arthrosc Relat Surg. 2008;24(1):77-81.

141. Koëter S, Diks MJF, Anderson PG, Wymenga AB. A modified tibial tubercle osteotomy for patellar maltracking. J Bone Jt Surg - Ser B. 2007;89(2):180-85.

142. Tjoumakaris FP, Forsythe B, Bradley JP. Patellofemoral instability in athletes: Treatment via modified fulkerson osteotomy and lateral release. Am J Sports Med. 2010;38(5):992-99.

143. Wang CJ, Chan YS, Chen HH, et al. Factors affecting the outcome of distal realignment for patellofemoral disorders of the knee. Knee. 2005;12(3):195-200.

144. Pritsch T, Haim A, Arbel R, et al. Tailored tibial tubercle transfer for patellofemoral malalignment: Analysis of clinical outcomes. Knee Surg Sports Traumatol Arthrosc. 2007;15(8):994-1002.

145. Payne J, Rimmke N, Schmitt LC, et al. The incidence of complications of tibial tubercle osteotomy: a systematic review. Arthrosc - J Arthrosc Relat Surg. 2015;31(9):1819-25. https://doi.org/10.1016/j.arthro.2015.03.028.

146. Burnham JM, Howard JS, Hayes CB, Lattermann C. Medial patellofemoral ligament reconstruction with concomitant tibial tubercle transfer: a systematic review of outcomes and complications. Arthrosc - J Arthrosc Relat Surg. 2016;32(6):1185-95. https://doi.org/10.1016/j.arthro.2015.11.039.

147. Drexler M, Dwyer T, Dolkart O, et al. Tibial rotational osteotomy and distal tuberosity transfer for patella subluxation secondary to excessive external tibial torsion: surgical technique and clinical outcome. Knee Surg Sports Traumatol Arthrosc. 2014;22(11):2682-89.

148. Matsushita T, Kuroda R, Oka S, et al. Clinical outcomes of medial patellofemoral ligament reconstruction in patients with an increased tibial tuberosity-trochlear groove distance. Knee Surg Sports Traumatol Arthrosc. 2014;22(10):2438-44

149. Nelitz M, Dreyhaupt J, Reichel $\mathrm{H}$, et al. Anatomic reconstruction of the medial patellofemoral ligament in children and adolescents with open growth plates: Surgical technique and clinical outcome. Am J Sports Med. 2013;41(1):58-63.

150. Batailler C, Neyret P. Trochlear dysplasia: Imaging and treatment options. EFORT Open Rev. 2018;3(5):240-47.

151. Duncan ST, Noehren BS, Lattermann C. The role of trochleoplasty in patellofemoral instability. Sports Med Arthrosc. 2012;20(3):171-80.

152. Von Knoch F, Böhm T, Bürgi ML, et al. Trochleaplasty for recurrent patellar dislocation in association with trochlear dysplasia: A 4- to 14-year follow-up study. J Bone Jt Surg - Ser B. 2006;88(10):1331-35.

153. Koh JL, Stewart C. Patellar instability. Clin Sports Med. 2014;33(3):461-76. https://doi.org/10.1016/j.csm.2014.03.011.

154. Banke IJ, Kohn LM, Meidinger G, et al. Combined trochleoplasty and MPFL reconstruction for treatment of chronic patellofemoral instability: a prospective minimum 2-year follow-up study. Knee Surg Sports Traumatol Arthrosc. 2014;22(11):2591-98

155. Donell ST, Joseph G, Hing CB, Marshall TJ. Modified Dejour trochleoplasty for severe dysplasia: Operative technique and early clinical results. Knee. 2006;13(4):266-73.

156. Faruqui S, Bollier M, Wolf B, Amendola N. Outcomes after trochleoplasty. lowa Orthop J. 2012;32:196-206.

157. Longo UG, Ciuffreda M, Locher J, et al. Treatment of primary acute patellar dislocation: systematic review and quantitative synthesis of the literature. Clin $\mathrm{J}$ Sport Med. 2017 Nov;27(6):511-23.
158. Testa EA, Camathias C, Amsler F, et al. Surgical treatment of patellofemoral instability using trochleoplasty or MPFL reconstruction: a systematic review. Knee Surg Sports Traumatol Arthrosc. 2017;25(8):2309-20.

159. McNamara I, Bua N, Smith TO, et al. Deepening trochleoplasty with a thick osteochondral flap for patellar instability. Am J Sports Med. 2015;43(11):2706-13.

160. Metcalfe AJ, Clark DA, Kemp MA, Eldridge JD. Trochleoplasty with a flexible osteochondral flap. Bone Jt J. 2017;99B(3):344-50.

161. Utting MR, Mulford JS, Eldridge JDJ. A prospective evaluation of trochleoplasty for the treatment of patellofemoral dislocation and instability. J Bone Jt Surg Ser B. 2008;90(2):180-85

162. Boden BP, Pearsall AW, Garrett WEJ, et al. Patellofemoral instability: evaluation and management. J Am Acad Orthop Surg. 1997 Jan;5(1):47-57.

163. Seeley MA, Knesek M, Vanderhave KL. Osteochondral injury after acute patellar dislocation in children and adolescents. J Pediatr Orthop. 2013;33(5):511-18.

164. Hinton R. Primary, traumatic patella dislocation: Surgical indications. Sports Medicine Update. 2010 Sep/Oct:2-6.

165. Vavken $P$, Wimmer MD, Camathias $C$, et al. Treating patella instability in skeletally immature patients. Arthrosc. 2013 Aug;29(8):1410-22.

166. Kepler CK, Bogner EA, Hammoud S, et al. Zone of injury of the medial patellofemoral ligament after acute patellar dislocation in children and adolescents. Am J Sports Med. 2011 Jul;39(7):1444-49.

167. Nelitz M, Dornacher D, Dreyhaupt J, et al. The relation of the distal femoral physis and the medial patellofemoral ligament. Knee Surg Sports Traumatol Arthrosc. 2011 Dec;19(12):2067-71.

168. Hensler D, Sillanpaa PJ, Schoettle PB. Medial patellofemoral ligament: anatomy, injury and treatment in the adolescent knee. Curr Opin Pediatr. 2014 Feb;26(1):70-78.

169. Hennrikus W, Pylawka T. Patellofemoral instability in skeletally immature athletes. J Bone Joint Surg Am. 2013 Jan;95(2):176-83.

170. Deie M, Ochi M, Sumen Y, et al. Reconstruction of the medial patellofemoral ligament for the treatment of habitual or recurrent dislocation of the patella in children. J Bone Joint Surg Br. 2003 Aug;85(6):887-90.

171. Noyes FR, Albright JC. Reconstruction of the medial patellofemoral ligament with autologous quadriceps tendon. Arthrosc. 2006 Aug;22(8):904.e1-7

172. Sillanpää PJ, Mäenpää HM, Mattila VM, et al. A mini-invasive adductor magnus tendon transfer technique for medial patellofemoral ligament reconstruction: a technical note. Knee Surg Sports Traumatol Arthrosc. 2009 May;17(5):508-12.

173. Gomes JE. Comparison between a static and a dynamic technique for medial patellofemoral ligament reconstruction. Arthrosc. 2008 Apr;24(4):430-35.

174. Fondren FB, Goldner JL, Bassett FH 3rd. Recurrent dislocation of the patella treated by the modified Roux-Goldthwait procedure. A prospective study of forty-seven knees. J Bone Joint Surg Am. 1985 Sep;67(7):993-1005.

175. Marsh JS, Daigneault JP, Sethi P, Polzhofer GK. Treatment of recurrent patellar instability with a modification of the Roux-Goldthwait technique. J Pediatr Orthop. 2006;26(4):461-65

176. Grannatt K, Heyworth BE, Ogunwole O, et al. Galeazzi semitendinosus tenodesis for patellofemoral instability in skeletally immature patients. J Pediatr Orthop. 2012 Sep;32(6):621-25.

177. Kraus T, Lidder S, Švehlík M, et al. Patella re-alignment in children with a modified Grammont technique. Acta Orthop. 2012 Oct 1;83(5):504-10. https:// doi.org/10.3109/17453674.2012.736168. 